\title{
Pearls \& Oy-sters: Anisocoria Greater in the Dark: It's Not Just All About Horner Pupil
}

Emily Witsberger, MD, Sasha A. Mansukhani, MBBS, John J. Chen, MD, PhD, and M. Tariq Bhatti, MD

Neurology ${ }^{\circledR}$ 2021;96:719-722. doi:10.1212/WNL.0000000000011221

\section{Pearls}

- An initial step in the evaluation of anisocoria is assessing the pupillary light reflex. If a pupil is not responsive to light, then the near pupillary reflex needs to be evaluated. Unilateral light-near pupil dissociation occurs due to a lesion of the ciliary ganglion, postganglionic parasympathetic pathway, retina, or optic nerve.

\section{Oy-sters}

- In addition to a Horner pupil, anisocoria can be more pronounced in the dark with physiologic anisocoria, miosis due to posterior iris synechiae, pharmacologic miosis due to a parasympathomimetic agent (i.e., pilocarpine), traumatic miosis, iris ischemia, and a chronic Adie tonic pupil.

- Adie tonic pupil most frequently presents with a mydriatic pupil, light-near dissociation, vermiform iris sphincter muscle movement, and anisocoria greater in the light. However, a chronic Adie tonic pupil may be characterized by a miotic pupil, light-near dissociation, and anisocoria that is greater in the dark.

An asymptomatic 65-year-old patient with no prior ocular surgery but a history of hypertension, hyperlipidemia, and hypothyroidism was noted to have a left miotic pupil during a routine ophthalmic examination. The anisocoria was noted to be greater in the dark and was interpreted as a left Horner pupil. No pharmacologic testing was performed. Cranial MRI, cervical magnetic resonance angiography, and chest radiograph were all normal. She was referred to our neuroophthalmology clinic for a second opinion.

On examination, there was no blepharoptosis, no facial anhidrosis, eye movements were full, and cranial nerve $(\mathrm{CN})$ function was normal. In ambient light, the right pupil measured $4.5 \mathrm{~mm}$ and the left $3.5 \mathrm{~mm}$. In the dark, the right pupil measured $5.5 \mathrm{~mm}$ and the left $4.0 \mathrm{~mm}$. The right pupil was round and responded briskly to light. The left pupil was irregular in shape, reacted poorly to light, but responded to near effort. Slit-lamp examination revealed poor temporal and inferior segmental iris sphincter movement. Following near stimulation, the left pupil slowly enlarged to its baseline size (video 1). The clinical findings were consistent with a longstanding or chronic Adie tonic pupil and no further intervention was required.

\section{Discussion}

Anisocoria, or $>0.4 \mathrm{~mm}$ difference in pupil size, is a common clinical scenario representing a range of etiologies (figure). The most common cause is physiologic anisocoria, with an estimated prevalence of $15 \%-30 \%$ in the general population. ${ }^{1}$ In physiologic anisocoria, the pupil size difference is no larger than $1-2 \mathrm{~mm}$ and is typically the same in dark and light conditions. However, in some cases it can be more pronounced in the dark but the pupillary light reaction is intact and equal between the 2 eyes. ${ }^{2}$

\author{
Correspondence \\ Dr. Bhatti \\ Bhatti.Muhammad@ \\ mayo.edu
}

MORE ONLINE

๑ Video

From the Departments of Ophthalmology (E.W., S.A.M., J.J.C., M.T.B.) and Neurology (J.J.C., M.T.B.), Mayo Clinic College of Medicine, Rochester, MN.

Go to Neurology.org/N for full disclosures. Funding information and disclosures deemed relevant by the authors, if any, are provided at the end of the article. 


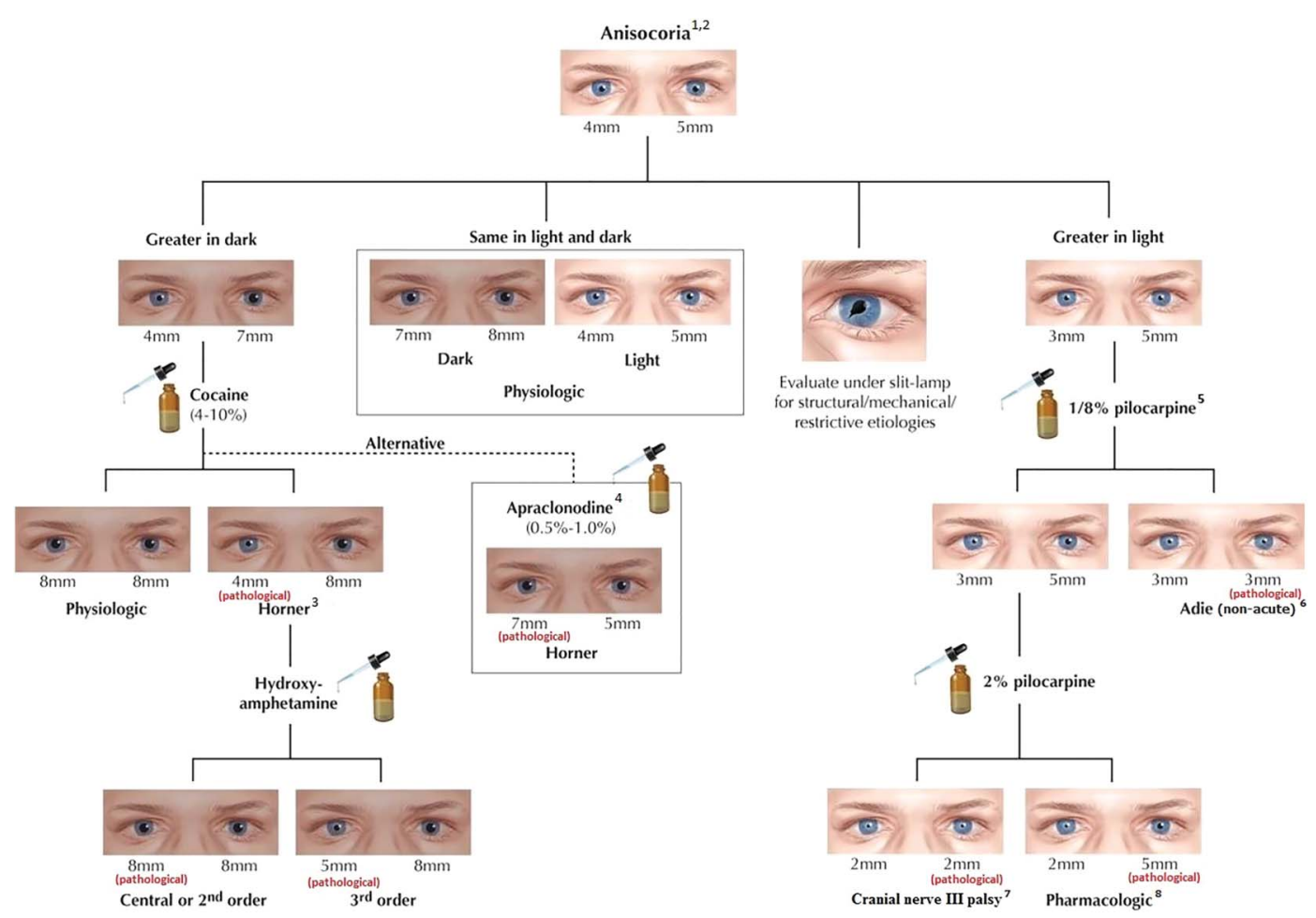

(1) Size of the pupils indicated is only a representative measure and does not indicate the absolute pupil size for a patient seen clinically. (2) If the light reflex is absent or poor, the presence or absence of the near reflex must be assessed. (3) Post-test anisocoria $>0.8 \mathrm{~mm}$ indicates a positive result. (4) Result should be assessed at a minimum of 45 minutes after instilling apraclonidine. Positive test is indicated by a reversal of anisocoria and improvement of ptosis. (5) Can be positive in a preganglionic cranial nerve III palsy. (6) Light-near pupil dissociation and segmental paresis of iris sphincter muscle (vermiform movement). (7) Cranial nerve III palsy will also manifest with upper eyelid ptosis and external ophthalmoplegia. (8) Pupil may react to $1 \%-2 \%$ pilocarpine if the muscarinic blocking activity of the offending agent is wearing off. Reproduced with permission from Bhatti MT, Schmalfus I. Handbook of Neuroimaging for the Ophthalmologist. London, UK: JP Medical Publishers Ltd; 2014.

In general, anisocoria that is greater in the dark indicates disruption of the oculosympathetic pathway (i.e., Horner pupil), resulting in a miotic pupil that dilates slowly (i.e., dilation lag) following removal of light stimulus. The pupillary light reaction is intact. Additional clinical features include an ipsilateral upper and lower "upside-down" blepharoptosis and facial anhidrosis (with a first- or second-order neuron lesion). Pharmacologic testing with either topical cocaine or apraclonidine can assist in establishing the diagnosis. Neuroimaging of the entire oculosympathetic system from the hypothalamus to the lower cervical-upper thoracic spinal cord including the cervical internal carotid artery is recommended, although only $20 \%$ of cases will have abnormal neuroimaging findings. ${ }^{3}$

If the anisocoria is greater in the dark but the miotic pupil does not react to light, this excludes a Horner pupil and expands the differential diagnosis to parasympathomimetic pharmacologic anisocoria, chronic miotic Adie tonic pupil, CN III aberrant regeneration, iris trauma (i.e., traumatic miosis), iris ischemia, or posterior synechiae. ${ }^{4}$ Pharmacologic miosis due to a parasympathomimetic or sympatholytic agent is often encountered in a patient with unilateral glaucoma being treated with pilocarpine or brimonidine. In cases of longstanding iris inflammation, prostaglandin release may cause pupillary miosis and formation of posterior iris synechiae preventing normal pupillary dilation best seen with the slit-lamp. Iris sphincter dysfunction may also result from anterior chamber inflammation and iris trauma following blunt globe injury, or ischemia as seen in acute angle closure glaucoma. In all these scenarios there will be impaired pupillary reaction to both light and near effort, whereas a patient with an Adie tonic pupil will have lightnear dissociation. CN III aberrant regeneration, also known as oculomotor synkinesis, presents clinically with pupillary constriction with eye movement (gaze-evoked pupillary constriction), or upper eyelid elevation on attempted downgaze.

Since the early 1800 s, numerous physicians wrote of a myotonic pupil developing in an apparently healthy person following an initial phase of iridoplegia. ${ }^{5}$ In 1931, William John Adie published a report of 6 patients with a benign, asymptomatic, and usually unilateral pupillary disorder characterized by pupil reactivity to accommodation but not to light. ${ }^{6} \mathrm{He}$ stressed the importance of differentiating this type of pupillotonia that now bears his name from the Argyll-Robertson pupil associated with neurosyphilis. Unlike the bilateral miotic 
Argyll-Robertson pupils, which constrict to near stimulation only, Adie noted that patients with pupillotonia had unilateral pathology in $80 \%$ of cases, irregular pupil margins, and more distinct light-near dissociation with tonic dilation following near reaction. Similar reports by several other neurologists were published around the same time, including observations by Gordon Holmes regarding the association of the myotonic pupil with other neurologic symptoms including weak or absent deep tendon reflexes and orthostatic hypotension (Holmes-Adie syndrome). ${ }^{7}$ Adie tonic pupil tends to affect young to middle-aged female patients, with an average age at onset of 32 years and an estimated prevalence of $0.02 \%$. In about $20 \%$ of cases, the fellow pupil may become involved at some time in the future. ${ }^{8}$ The Adie tonic pupil results from decreased neural input to the iris sphincter muscle from second-order parasympathetic neurons following damage to the ciliary ganglion ultimately resulting in denervation supersensitivity. ${ }^{9}$ By definition, an Adie tonic pupil or HolmesAdie syndrome is an idiopathic condition, although a tonic pupil can be caused by local orbital trauma, autonomic dysfunction, herpes zoster or herpes simplex virus infection, or botulism toxicity. ${ }^{4}$

Clinically, an Adie tonic pupil is characterized by poor to absent light reflex, intact near response, and segmental paresis of the iris sphincter muscle described as a vermiform movement. In the acute phase, both the light reflex and near response are severely impaired, but the near response improves over several months due to aberrant regeneration. The majority of the parasympathetic fibers in CN III serve a role in accommodation, and their selective regeneration following injury leads to the characteristic light-near dissociation seen in Adie tonic pupil. Pupillary constriction to a near target is slow and sustained, and following accommodative constriction, the pupil slowly redilates. Denervated segments of the iris stoma appear thin, and in $90 \%$ of cases more than two-thirds of the iris sphincter is affected. ${ }^{5}$ The iris sector palsy results from uneven distribution of postganglionic innervation to the iris sphincter muscle, leading to the characteristic slow and segmental constriction following light stimulation. ${ }^{5}$ Pharmacologic testing with topical cocaine results in dilation of an Adie tonic pupil as the sympathetic chain is not affected, whereas a patient with Horner syndrome will have no to minimal response to cocaine in the affected eye. Due to cholinergic supersensitivity, instillation of dilute $(0.125 \%)$ pilocarpine will cause the tonic pupil to constrict, while there is no effect on the normal pupil. The postsynaptic receptor density significantly increases following an ocular autonomic neuropathy, producing an exaggerated response to eye drop testing. This phenomenon develops within 5 to 7 days following the denervation, although the exact timing is not known. Of note, caution should be applied to the interpretation of the dilute pilocarpine test due to its limited specificity. Anisocoria due to a preganglionic CN III lesion may also yield a positive test in up to two-thirds of cases. ${ }^{10}$ Furthermore, in the situation of an acute $(<2$ months) Adie tonic pupil, the dilute pilocarpine test may be negative.

In approximately $25 \%$ cases of an Adie tonic pupil, the affected pupil decreases in size by $2-3 \mathrm{~mm}$ over the course of several years. ${ }^{5}$ In this case, the abnormal pupil becomes the miotic pupil (referred to colloquially as "the little old Adie's pupil"), and the anisocoria is more pronounced in the dark rather than light. The tonic pupil in all cases is characterized by slow redilation following light stimulus (if this reflex is at all preserved) or near reaction. A chronic miotic Adie tonic pupil maintains this characteristic slow redilation. Thus, compared to the dilation of the normal pupil in a dark setting, the chronic miotic Adie tonic pupil will remain relatively more constricted. It has been theorized that an Adie tonic pupil becomes miotic over time due to an increase in reinnervated fibers to the iris sphincter muscle and tonic contraction from accommodative fibers. ${ }^{4}$ Infrequently $(<2 \%)$, an acute Adie tonic pupil may present with a miotic pupil, which has been termed primary miotic Adie tonic pupil. ${ }^{5}$ In both a chronic Adie and primary miotic Adie tonic pupil, there will be light-near dissociation with sectoral iris muscle palsy.

Our case highlights the importance of assessing the pupillary light reflex and careful visualization of the pupil movement in a patient with anisocoria. The anisocoria in both a Horner pupil and many chronic Adie tonic pupils is more pronounced in the dark. However, a crucial difference between these 2 disorders is the intact pupillary light reflex in a Horner pupil and light-near dissociation in an Adie tonic pupil. Identifying the difference between these 2 disorders can avoid unnecessary testing.

\section{Study Funding}

Mayo Foundation.

\section{Disclosure}

The authors report no disclosures relevant to the manuscript. Go to Neurology.org/N for full disclosures.

\section{Appendix Authors}

\begin{tabular}{|c|c|c|}
\hline Name & Location & Contribution \\
\hline $\begin{array}{l}\text { Emily } \\
\text { Witsberger, } \\
\text { MD }\end{array}$ & $\begin{array}{l}\text { Mayo Clinic, } \\
\text { Rochester, } \\
\text { MN }\end{array}$ & $\begin{array}{l}\text { Major role in drafting the manuscript } \\
\text { and video }\end{array}$ \\
\hline $\begin{array}{l}\text { Sasha A. } \\
\text { Mansukhani, } \\
\text { MBBS }\end{array}$ & $\begin{array}{l}\text { Mayo Clinic, } \\
\text { Rochester, } \\
\text { MN }\end{array}$ & $\begin{array}{l}\text { Revised the manuscript for intellectual } \\
\text { content }\end{array}$ \\
\hline $\begin{array}{l}\text { John J. Chen, } \\
\text { MD, PhD }\end{array}$ & $\begin{array}{l}\text { Mayo Clinic, } \\
\text { Rochester, } \\
\text { MN }\end{array}$ & $\begin{array}{l}\text { Revised the manuscript for intellectual } \\
\text { content }\end{array}$ \\
\hline $\begin{array}{l}\text { M. Tariq } \\
\text { Bhatti, MD }\end{array}$ & $\begin{array}{l}\text { Mayo Clinic, } \\
\text { Rochester, } \\
\text { MN }\end{array}$ & $\begin{array}{l}\text { Designed and conceptualized study, } \\
\text { revised the manuscript for intellectual } \\
\text { content }\end{array}$ \\
\hline
\end{tabular}




\section{References}

1. Lam BL, Thompson HS, Corbett JJ. The prevalence of simple anisocoria. Am J Ophthalmol 1987;104:69-73.

2. Thompson S, Pilley SF. Unequal pupils: a flow chart for sorting out the anisocorias. Surv Ophthalmol 1976;21:45-48.

3. Beebe JD, Kardon RH, Thurtell MJ. The yield of diagnostic imaging in patients with isolated Horner syndrome. Neurol Clin 2017;35:145-151.

4. Miller NR, Newman NJ, Biousse V, Kerrison JB, eds. . In: Walsh and Hoyt Clinical Neuro-Ophthalmology, 6th ed. Baltimore: Williams \& Wilkins; 2005.

5. Loewenfeld IE. The Pupil: Anatomy, Physiology, and Clinical Applications. Detroit: Wayne State University Press; 1993.
6. Adie WJ. Pseudo-Argyll Robertson pupils with absent tendon reflexes: a benign disorder simulating tabes dorsalis. Br Med J 1931;1:928-930.

7. Holmes G. Partial iridoplegia with symptoms of other diseases of the nervous system. Trans Ophthalmol Soc UK 1931;51:209-228.

8. Thompson HS. Adie's syndrome: some new observations. Trans Am Ophthalmol Soc 1977;75:587-626.

9. Kardon RH, Corbett JJ, Thompson HS. Segmental denervation and reinnervation of the iris sphincter as shown by infrared videographic transillumination. Ophthalmology 1998;105:313-321.

10. Jacobson DM. Pupillary responses to dilute pilocarpine in preganglionic 3rd nerve disorders. Neurology 1990;40:804-808.

\section{Disputes \& Debates: Rapid online correspondence}

The editors encourage comments on recent articles through Disputes \& Debates:

Access an article at Neurology.org/ $\mathrm{N}$ and click on "MAKE COMMENT" beneath the article header. Responses will be posted as rapidly as possible.

Before submitting a comment to Disputes \& Debates, remember the following:

- Disputes \& Debates is restricted to comments about articles published in Neurology within the last 8 weeks

- Read previously posted comments; redundant comments will not be posted

- Your submission must be 200 words or less and have a maximum of 5 references; the first reference must be the article on which you are commenting

- You can include a maximum of 5 authors (including yourself)

\section{Visit the Neurology $y^{\circledast}$ Resident \& Fellow Website}

Click on Residents \& Fellows tab at Neurology.org.

Now offering:

- Neurology ${ }^{\circledR}$ Resident \& Fellow Editorial team information

- "Search by subcategory" option

- E-pearl of the Week

- RSS Feeds

- Direct links to Continuum ${ }^{\circledR}$, Career Planning, and AAN Resident \& Fellow pages

- Recently published Resident \& Fellow articles

- Podcast descriptions

- Blogs by Editors and Resident \& Fellow team members

f Find Neurology ${ }^{\circledR}$ Residents \& Fellows Section on Facebook: facebook.com/AANResidentsAndFellows

Follow Neurology ${ }^{\circledR}$ on Twitter: @GreenJournal \#NeurologyRF

(0) Find Neurology ${ }^{\circledR}$ Residents \& Fellows Section on Instagram: @aanbrain \#NeurologyRF 


\section{Neurology}

\section{Pearls \& Oy-sters: Anisocoria Greater in the Dark: It's Not Just All About Horner Pupil \\ Emily Witsberger, Sasha A. Mansukhani, John J. Chen, et al.}

Neurology 2021;96;719-722 Published Online before print November 18, 2020

DOI 10.1212/WNL.0000000000011221

This information is current as of November 18, 2020

\section{Updated Information \&} Services

References

Subspecialty Collections

Permissions \& Licensing

Reprints including high resolution figures, can be found at: http://n.neurology.org/content/96/15/719.full

This article cites 8 articles, 2 of which you can access for free at: http://n.neurology.org/content/96/15/719.full\#ref-list-1

This article, along with others on similar topics, appears in the following collection(s):

Clinical neurology examination

http://n.neurology.org/cgi/collection/clinical_neurology_examination Pupils

http://n.neurology.org/cgi/collection/pupils

Information about reproducing this article in parts (figures,tables) or in its entirety can be found online at:

http://www.neurology.org/about/about_the_journal\#permissions

Information about ordering reprints can be found online:

http://n.neurology.org/subscribers/advertise

Neurology ${ }^{\circledR}$ is the official journal of the American Academy of Neurology. Published continuously since 1951, it is now a weekly with 48 issues per year. Copyright @ 2020 American Academy of Neurology. All rights reserved. Print ISSN: 0028-3878. Online ISSN: 1526-632X.

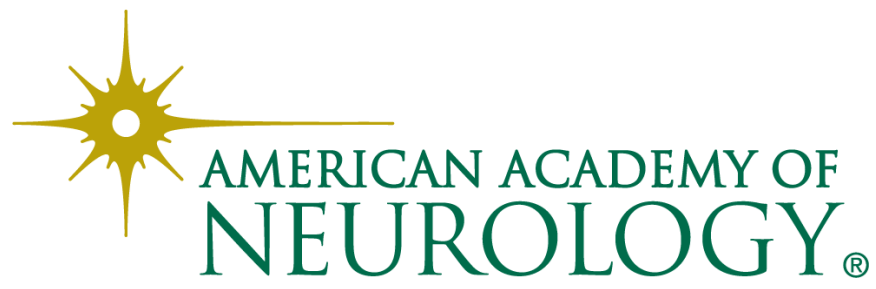

